\title{
pro.posições
}

$e$-ISSN 1980-6248

http://dx.doi.org/10.1590/1980-6248-2016-0046

ARTIGOS

\section{Identidade do eu em contextos plurais: desafios da formação}

\section{Identity of the self in plural contexts: challenges of formation}

\author{
Cledes Antonio Casagrande (i)
}

Nadja Hermann (ii)

\begin{abstract}
(i) Universidade La Salle - UNILASALLE, Canoas, RS, Brasil, cledescasagrande@gmail.com
(ii) Grupo de pesquisa "Racionalidade e Formação", Porto Alegre, RS, Brasil, nadjamhermann@gmail.com
\end{abstract}

Resumo: O presente ensaio, resultante de pesquisa na área da Filosofia da Educação, reflete sobre os desafios da formação da identidade do eu em contextos plurais e de multiplicidade normativa. Para tanto, recorre-se aos aportes teóricos de G. H. Mead e de J. Habermas, especialmente às noções de interacionismo simbólico e de agir comunicativo, a fim de evidenciar o papel da educação na formação de selves em contextos sociais. Desse modo, destaca-se a relevância da interação e da socialização tanto no desenvolvimento de um autoentendimento mediado quanto na estabilização de uma noção de self. Entende-se que, para superar os desafios inerentes à pluralidade contemporânea, assumem destacada importância as experiências formativas escolares e as aprendizagens contínuas. Ambas contribuem para o desenvolvimento moral, o processo de descentramento do eu e a estabilização de uma identidade pessoal mais condizente com os pressupostos e as exigências da atual vida em sociedade.

Palavras-chave: formação, identidade, interacionismo simbólico, agir comunicativo 


\title{
pro.posições
}

$e$-ISSN 1980-6248

http://dx.doi.org/10.1590/1980-6248-2016-0046

Abstract: From a research in the field of Philosophy of Education, this essay reflects upon the challenges of the identity formation of the self in plural contexts and in contexts of normative multiplicity. Therefore, the theoretical contributions of G. H. Mead and J. Habermas are used, especially the notions of symbolic interaction and communicative action, in order to evidence the role of education in the process of the formation of the self in social contexts. Thus, the paper highlights the relevance of interaction and socialization both in the development of a mediated selfunderstanding and in the stabilization of a notion of self. As this research indicates, the formative experiences at school and the ongoing learning assume a significant importance in overcoming the challenges pertaining to the contemporary plurality. Both contribute to the moral development, to the process of decentralization of the self, and to the stabilization of a personal identity better suited to the presuppositions and requirements of today's life in society.

Keywords: Formation, identity, symbolic interaction communicative action

\begin{abstract}
Sou eu, eu mesmo, tal qual resultei de tudo,
Espécie de acessório ou sobressalente próprio, Arredores irregulares da minha emoção sincera,
\end{abstract}

Sou eu aqui em mim, sou eu.

Fernando Pessoa (1999)

[Poesias de Álvaro de Campos]

\section{Introdução}

Michel de Montaigne (1972) mostra, já no século XVI, o quanto o autoentendimento é obscuro, pois o homem é um ser multiforme, não um só, mas "de natureza muito pouco definida, estranhamente desigual e diverso" (p. 14). Ao mesmo tempo em que passa a ser o centro da problemática filosófica, o homem pouco sabe de si mesmo, o que revela a dificuldade em tematizar como ele se autodetermina diante dos múltiplos papéis e dos desejos. O modelo mais conhecido de autoentendimento é aquele que compreende a autoconsciência como uma relação reflexiva entre o sujeito e ele mesmo, como objeto. Isto é, o próprio sujeito se autorrepresenta como ser que pensa e age autonomamente. Só mais tardiamente, no século XX, a consciência de si mesmo passa a ser interpretada no plano prático. George Herbert Mead altera, pela base, o autoentendimento tradicional, porquanto o que ele chama de self ou si mesmo se constitui simbolicamente, na relação com os outros. Jürgen Habermas, influenciado por Mead, acentua que a individuação tem sua gênese na socialização, pois entende que a formação da identidade ocorre em situações de interação simbólica, especialmente por meio da fala. 


\section{pro.posições}

$e$-ISSN 1980-6248

http://dx.doi.org/10.1590/1980-6248-2016-0046

A dimensão intersubjetiva do autoentendimento e os processos formativos nela implicados constituem o objeto das considerações que seguem. Destarte, o presente ensaio tem como objetivo discutir o processo de formação da identidade pessoal ${ }^{1}$ como um autoentendimento simbólico mediado linguisticamente, em contextos de pluralidade de formas de vida e de multiplicidade normativa. Além disso, quer refletir sobre a forma como a educação contemporânea - especialmente a escolar - pode contribuir, através dos processos de aprendizagem e de socialização, para a formação e a estabilização de uma autocompreensão que faça frente aos desafios de uma sociedade multicultural, globalizada e pós-metafísica.

Os desafios do autoentendimento e da estabilização da identidade pessoal constituemse em problemas fundamentais e recorrentes na história ocidental, tanto para indivíduos e sociedades quanto para a tematização filosófica no campo educacional. Desde o enunciado délfico-socrático do "conhece-te a ti mesmo" (Platão, 1997, p. 774 [Protágoras, 343b]), os homens têm empreendido uma longa jornada à procura de um discurso que forneça sentido à própria existência. Trata-se de um movimento de busca por si mesmo, a partir das mediações históricas das relações que o ser humano estabeleceu com os outros, com a cultura e com o meio no qual estava inserido.

Esse processo de compreensão de si percorreu um longo caminho, que incluiu a luta entre a orientação à divindade, vigente na época medieval, e a afirmação do homem como razão autônoma, que emergiu no Renascimento e consolidou-se a partir do século XVIII. Com tal processo, definiram-se os contornos de uma nova subjetividade, para a qual a ordem do mundo, não mais imposta por um criador, e a busca da liberdade sob os auspícios da razão criaram as condições para um novo processo autobiográfico, refletido em todos os âmbitos da cultura, da ciência e da sociedade. Como exemplo, podemos lembrar a arte do retrato e do autorretrato, na qual o indivíduo passa a ser visível para si mesmo, num empenho de autorreflexão antropológica (Dölmen, 2001). Nesse caso, a arte demonstra a nova ordem emergente, tornando visível o homem para ele mesmo.

A história do pensamento ocidental vincula-se a uma busca autoexpressiva, discursiva e artística de autoentendimento, pois o homem, ainda que de modo inconsciente, nega-se a viver

\footnotetext{
1 Neste ensaio, devido à proximidade teórica, utilizaremos os termos identidade e self como equivalentes, do seguinte modo: ao utilizarmos self, nos referimos, preponderantemente, aos escritos de G. H. Mead; ao referirmonos ao conceito de identidade, indicamos uma maior proximidade dos escritos de J. Habermas.
} 


\section{pro.posições}

$e$-ISSN 1980-6248

http://dx.doi.org/10.1590/1980-6248-2016-0046

uma vida sem sentido, sem compreender os elementos e as circunstâncias que o constituem e sem projetar-se ao futuro. A pergunta acerca de si mesmo engendra uma preocupação ética com o transcorrer da própria existência e, ao mesmo tempo, remete a uma projeção ao futuro, a um desejo de completude, que o impulsiona a aprender a viver, já que "a vida sem exame não é vida digna de um ser humano" (Platão, 1997, p. 33 [Apologia, 38a]). Ou seja, é fundamental ao homem inquirir sobre o sentido do próprio existir, respondendo à questão: "o que devo fazer com o tempo de minha vida?" (Habermas, 2003, p. 03). Essa pergunta leva a outras questões, em torno das quais orbita o problema da formação da identidade dos sujeitos: "como devemos nos compreender, quem somos e quem queremos ser" (Habermas, 2003, p. 06).

Percebemos, então, evidências históricas de uma busca existencial e vestígios de um exercício prático-espiritual discursivo, com mais de dois mil anos de história, por meio dos quais o homem procurou entender-se e reler o desenrolar de sua existência na tentativa de atribuir significado e sentido ao modo como construiu a própria história, como se biografou, quais discursos construiu acerca de si e por que se tornou o que é2. Tais questões continuam atuais e mantêm-se válidas diante dos desafios que a sociedade contemporânea impõe aos seus atores, especialmente no que concerne aos processos de formação da identidade pessoal (NunnerWinkler, 2011) em contexto pós-metafísico.

Concomitante a esse arcabouço teórico-prático discursivo referente ao autoentendimento, é importante destacar que a sociedade ocidental, em momentos distintos de sua história, estruturou formas de auxiliar as novas gerações a moldar a própria existência a partir de projetos formativos, institucionalizados na educação ${ }^{3}$. Isto é, por intermédio da educação, as novas gerações poderiam ser formadas de acordo com um projeto social mais amplo e intencional, de modo a não permanecerem sujeitas à própria sorte.

Atualmente, o problema da formação do eu e da estabilização de uma identidade abarca uma gama de questões ainda em aberto, como: poderia o desenvolvimento de um autoentendimento mais ajustado às condições da sociedade atual facultar ao sujeito viver de

\footnotetext{
2 Nessa expressão ressoa o verso da II Pítica, de Píndaro (1947), que diz "aprenda a ser o que você é" (p. 50), exortando o homem a aprender de si mesmo e a superar-se. Trata-se de uma das influências da tradição espiritual presente na Antiguidade grega e na filosofia helenística, em que o homem se transforma por meio de práticas espirituais.

${ }^{3}$ As noções de Paideia, Humanitas e Bildung são exemplos desse processo de estruturação de um discurso formativo amplo, com implicações concretas para a educação. Sugerimos conferir a coletânea Sobre filosofia e educação: racionalidade, diversidade e formação pedagógica (Cenci, Dalbosco, \& Mühl, 2009).
} 


\section{pro.posıções}

$e$-ISSN 1980-6248

http://dx.doi.org/10.1590/1980-6248-2016-0046

modo mais autêntico, com a possibilidade de configurar um projeto existencial consciente e estabilizar uma identidade pessoal? Tem a educação escolar alguma responsabilidade no que tange aos processos de estruturação da identidade pessoal? Uma resposta positiva a essas perguntas nos levaria a questionar o alcance e os limites do papel da escola. Ademais, seria necessário 'remar contra a maré' de grande parte da produção teórica do campo educacional brasileiro, mais atenta à ideia de que "a educação se resolve no plano das competências e do desenvolvimento tecnológico" (Hermann, 2014b, p. 15). Ou seja, teríamos que transpor o discurso e a reflexão ao campo teórico-prático, em busca dos pressupostos que estruturam um projeto educacional.

Para discutir o tema proposto, principiaremos com uma aproximação à questão da formação da identidade pessoal desde a perspectiva da pluralidade e da multiplicidade normativa. A partir das contribuições de G. H. Mead e de J. Habermas, refletiremos acerca da formação da identidade pessoal em contextos simbólicos e interativos. Com isso, evidenciaremos a centralidade da socialização, da interação e da aprendizagem na constituição do self e na estabilização de uma identidade do eu. Finalmente, abordaremos a relação entre educação e identidade desde a perspectiva de suas implicações formativas.

Ressaltamos que este texto é derivado de pesquisas realizadas pelos autores no decorrer dos últimos anos, especialmente aquelas que refletem acerca dos pressupostos que dão sustentação a projetos e processos educacionais na contemporaneidade (Hermann, 2001, 2014a, 2014b, 2005). Entre esses pressupostos, percebemos que a relação entre educação e autoentendimento, nas perspectivas do interacionismo simbólico (Casagrande, 2012, 2014) e da teoria do agir comunicativo (Casagrande, 2009; Hermann, 1999;), merece uma ampliação da abordagem, tal qual nos propomos aqui.

\section{Formação, pluralidade e estabilização de uma identidade pessoal: uma aproximação ao problema}

A pluralidade de orientações valorativas presente nas sociedades contemporâneas e as múltiplas possibilidades de escolhas afetam a construção da identidade porque demandam do indivíduo um processo contínuo de reorganização de suas experiências e decisões, de modo a 


\section{pro.posições}

$e$-ISSN 1980-6248

http://dx.doi.org/10.1590/1980-6248-2016-0046

constituir uma identidade de si mesmo que não se esgota em um único modelo, mas exige uma articulação criativa. Essa articulação, em busca de sentido e de significado, pressupõe considerar a circunscrição histórica, a pluralidade de experiências vitais e o exercício prático da intersubjetividade, isto é, implica colocar-se em relação com os outros sujeitos que tomam parte de nossa experiência vital, bem como com as condições objetivas da sociedade da qual participamos.

A busca por sentido e significado não é um fenômeno individual restrito a uma sociedade ou a uma época histórica. Esse exercício hermenêutico, existencial e normativo, institucionalizou-se em projetos formativos assumidos por distintas sociedades em diferentes contextos, com validade universal. Como exemplo disso, temos os ideais formativos da Paideia, da Humanitas e da Bildung. Ocorre que esses três projetos formativos possuíam um substrato metafísico de sustentação, com um ideal de ser humano unitário e predeterminado, que aos poucos sofreu um processo de perda de sua força normativa e de seu valor social vinculante. A crítica aos conceitos clássicos de formação ocorreu pari passu à contestação ao conceito de razão da modernidade, especialmente à centralidade atribuída à subjetividade.

Além disso, houve um processo crescente de questionamentos e de dúvidas acerca de velhos ideais, valores e certezas, os quais nortearam o existir e a práxis dos sujeitos no decorrer dos séculos. O atual contexto histórico-social, caracterizado por formas de pensar pósmetafísicas, flexibiliza os fundamentos subjetivos e sociais outrora vigentes, liquefazendo as fronteiras dos referenciais éticos, estéticos e epistêmicos do agir e do existir, culminando numa pluriversalidade de referências e de pressupostos. Por isso, o problema do autoentendimento individual apresenta-se difícil de ser equacionado, porquanto as noções de self e de identidade perderam suas referências tradicionais, sendo despidas dos valores da tradição e de fundamentação metafísica ${ }^{4}$.

Axel Honneth (2009) reconhece que a crise do conceito clássico de subjetividade decorre de um movimento crítico que possui duas vertentes clássicas. A primeira, ligada a Freud, a Nietzsche e ao Romantismo alemão, demonstra a existência de forças e de impulsos pessoais

\footnotetext{
${ }^{4}$ Ressaltamos que um contexto dessa ordem traz impactos à educação, especialmente na medida em que a ausência de um pensamento totalizador e de fins educativos pode gerar uma situação de desamparo e o risco de anything goes, em que não há mais critérios para definir o que seria mais adequado ao processo educativo. De nossa parte, entendemos que "não é possível educar num relativismo absoluto, sem reunir esforços, na perspectiva de estabelecer validade para a tarefa educativa, enquanto formação humana” (Hermann, 1999, p.121).
} 


\section{pro.posições}

$e$-ISSN 1980-6248

http://dx.doi.org/10.1590/1980-6248-2016-0046

que escapam ao controle da razão ou da consciência do indivíduo, comprovando que "o sujeito não pode ser transparente para si mesmo da maneira como se afirma pela ideia clássica de autonomia" (Honneth, 2009, p. 275). A segunda, vinculada a Wittgenstein, a Saussure e à Filosofia da Linguagem, contesta a capacidade de o sujeito individualmente ser o criador de sentidos e de significados, negando, com isso, "a ideia de autonomia no sentido da autoria do sujeito" (p. 276). O que se percebe é que tanto o conceito de inconsciente quanto a compreensão do papel e do mecanismo da linguagem indicam a impossibilidade de que, ao atuar ou participar da vida social, o indivíduo detenha um controle completo sobre si mesmo, sobre suas ações e até mesmo sobre sua autocompreensão. Essas duas críticas representam um duro golpe ao conceito de subjetividade transcendental, que entra em crise.

Tal contexto enseja, também, uma crise narcísica por meio da qual o ser humano reconhece não ser totalmente transparente a si, tampouco dono de suas ações. Sugere certo sentimento de insegurança no tocante à própria biografia, como uma reta autocompreensão. Assim, agudizam-se as dificuldades de estabilização de uma identidade pessoal. Ao analisar essa questão, Gertrud Nunner-Winkler (2011) afirma:

Nas sociedades tradicionais, a identidade é instituída e estabilizada através de arranjos socioestruturais. $\mathrm{Na}$ modernidade clássica, a identidade é escolhida pelo indivíduo, mas estabilizada socioestruturalmente. Nas sociedades pós-modernas ou de modernidade tardia, a identidade é escolhida pelo indivíduo, que produz sua estabilização através do tempo. Há, no entanto, condições que, notadamente, dificultam esse processo: a mudança rápida, a multiplicação das opções e a possibilidade de revisão de decisões já tomadas. (p. 57)

Diferentemente das sociedades tradicionais e das sociedades modernas, as sociedades contemporâneas pressupõem configurações de identidade do eu, decisões morais e participação social num cenário de pluralidade cultural e de relativismo prático. Dos sujeitos exigem-se, cada vez mais, decisões práticas, modos de vida e inserções em grupos e instituições diferenciados e, até mesmo, contraditórios entre si. São mudanças que afetam as "condições empíricas da ação moral e das demandas sociais de moralidade" (Edelstein \& Nunner-Winkler, 2005, p. 01) e, ao mesmo tempo, aumentam a relevância do julgamento moral, abalando os modos tradicionais de estabilização de um sentido de si mesmo. Entre as principais mudanças, Edelstein e NunnerWinkler (2005) destacam a secularização, o processo científico e tecnológico, a globalização, a individualização e a pluralização. 


\section{pro.posıções}

$e$-ISSN 1980-6248

http://dx.doi.org/10.1590/1980-6248-2016-0046

Entretanto, mesmo num contexto pós-metafísico de legitimação da ação prática e do pensar pedagógico, entendemos que não é possível renunciar ao exercício do conceito e da busca por pressupostos que auxiliem na organização de processos educacionais mais condizentes com as exigências da vida em sociedade hoje. Nesse sentido, alinhamo-nos ao seguinte alerta de Habermas (2004c): "defendo a ideia de que o pensamento pós-metafísico deve impor a si próprio uma moderação, quando se trata de tomar posições definitivas em relação a questões substanciais sobre a vida boa ou não-fracassada" (p. 01). Importa, pois, no horizonte do problema que nos dispomos a discutir, avançar na busca por pressupostos, mesmo que em sentido fraco, que auxiliem a compreender os processos formativos da identidade pessoal, tal qual nos apontam G. H. Mead e J. Habermas.

\section{A formação da identidade em contextos interativos: alguns aportes de Mead e de Habermas}

George Herbert Mead e Jürgen Habermas possuem uma compreensão complementar quanto à gênese e à estabilização da identidade pessoal. Ambos apontam o processo de socialização como o desencadeador da individuação, uma vez que "as pessoas se individualizam apenas por meio da socialização" (Habermas, 2004b, p. 326). Ademais, concordam que a interação simbólica ${ }^{5}$ e a aprendizagem contínua são as responsáveis pelo desenvolvimento dos processos de estruturação da identidade.

Com efeito, a subjetividade, que é o que faz do corpo humano um recipiente animado da alma, se constitui a partir das relações intersubjetivas para com os outros. O si mesmo individual surge apenas com o auxílio social da exteriorização e também só pode se estabilizar na rede de relações intactas de reconhecimento [ênfase no original]. (Habermas, 2004c, p. 47)

A estruturação da identidade possui estágios progressivos de desenvolvimento. Neles, a identidade do eu num nível pós-convencional pode ser caracterizada como o estágio mais avançado do desenvolvimento moral, implicando plena responsabilidade, liberdade ética no pensar, no agir e no dizer. Alcançar tal estágio de desenvolvimento pressupõe processos de socialização e de individuação, descentramento, aprendizagem contínua, ganhos de

\footnotetext{
${ }^{5}$ Podemos identificar e aproximar o conceito de interação simbólica, de matriz pragmática e presente na obra de Mead, ao conceito de agir comunicativo (Habermas, 2002c, 2012a, 2012b).
} 


\section{pro.posıções}

$e$-ISSN 1980-6248

http://dx.doi.org/10.1590/1980-6248-2016-0046

racionalidade, liberdade e autorrealização. Como veremos na sequência, são preponderantes no processo de desenvolvimento da identidade: a individuação como socialização e a estruturação dialética do self; a aprendizagem e o agir comunicativo como elementos constitutivos da reprodução dos componentes do mundo da vida.

\section{[i] Socialização, individuação e a gênese do self}

Mead construiu uma compreensão original da formação do self, distinguindo-a das concepções modernas e relacionando-a com a intersubjetividade e a comunicação simbólica. Para Mead, o self constitui-se por meio de processos de socialização e de individuação progressivos, numa matriz intersubjetiva, simbólica e comunicativa ${ }^{6}$. A gênese e a estrutura do self são sociais porque "os indivíduos se convertem em um objeto para si mesmos, precisamente, porque descobrem a si mesmos adotando a atitude dos outros que estão envolvidos nas suas condutas" (Mead, 1981, pp. 283-284). Ao assumir os papéis sociais disponíveis, o sujeito internaliza as estruturas do self, permitindo o desenvolvimento de um autoentendimento mediado pela figura do outro ${ }^{7}$.

Habermas (2010) elogiou a originalidade de Mead, especialmente o fato de ele propor a compreensão da individuação através da socialização. Nesse sentido, afirmou: "Na psicologia social de G. H. Mead vejo esboçada a única tentativa com perspectiva de êxito para reproduzir no plano conceitual o pleno teor significante da individuação” (p. 213). Isso ocorre porque "Mead analisa fenômenos da consciência sob o ponto de vista de sua formação, que tem origem em estruturas da interação mediada pela linguagem e pelos símbolos” (Habermas, 2012b, p. 08).

Seguindo criticamente ${ }^{8}$ os passos pioneiros de Mead, Habermas (2004b) postula que o ser humano constitui-se mediante processos de aprendizagem, de socialização e de individuação

\footnotetext{
${ }^{6}$ Os principais escritos de Mead sobre esse tema estão compilados nas seguintes obras: Selected writings (Mead, 1981); On social psychology (Mead, 1984); Mind, self, and society (Mead, 1992); The philosophy of the present (Mead, 2002); Play, school, and society (Mead, 2006); The philosophy of education (Mead, 2008).

7 Por isso, a afirmação categórica de Sass (2004): “O self individual é organizado no interior do processo social” (p. 237).

${ }^{8}$ Habermas reconhece a importância de Mead, mas critica sua parcialidade na análise do processo de individuação ancorado na linguagem. Essa crítica ocorre porque "Mead não distingue nitidamente o nível da interação mediada por símbolos do nível da interação mediada pela linguagem e direcionada por normas" (Habermas, 2012b, p. 22). Além disso, "Mead não separou nitidamente o nível da interação através de símbolos do nível superior da comunicação mediada por uma linguagem diferenciada; ... Isso significa que ele acompanha o desenvolvimento da interação
} 


\section{pro.posıções}

$e$-ISSN 1980-6248

http://dx.doi.org/10.1590/1980-6248-2016-0046

que ocorrem no seio fecundo do mundo da vida e no recurso ao agir comunicativo, o que "permite o entrelaçamento de individuação e socialização" (p.96). O ser humano não nasce predefinido, e sim como uma possibilidade, sempre referido ao outro, à cultura e à sociedade. Diferencia-se das outras espécies animais por desenvolver-se simbolicamente, dotando de sentido a própria existência e o mundo ao seu redor ${ }^{9}$, e isso somente é possível pela linguagem, a qual pode ser, ao mesmo tempo, "meio do entendimento, meio da coordenação da ação e meio da socialização dos indivíduos" (Habermas, 2012b, p. 45).

É interessante destacar que, para ambos os autores, além dos elementos biológicos e hereditários, confluem com o processo de humanização elementos simbólicos, culturais e sociais. Ao nascer, o ser humano adentra em um mundo simbolicamente estruturado, no qual entrará em contato com outros seres humanos e com uma cultura específica. Desse contato, e mediante processos de aprendizagem, singulariza-se, ao mesmo tempo em que se socializa. Isso leva Habermas (2002d) a afirmar que "os organismos apenas se enquadram na descrição de pessoas se, e na medida em que estiverem socializados, ou seja, investidos de e estruturados por contextos de significado sociais e culturais" (p. 143).

Ao processo de individuação correspondem um maior grau de organização do ser humano e níveis mais elevados de racionalidade, visto que

as pessoas, enquanto sujeitos dotados da capacidade de linguagem e de ação, só se individualizam por via da socialização. Transformam-se em indivíduos na medida em que crescem no seio de uma comunidade linguística e, por conseguinte, num universo partilhado intersubjetivamente.... A pessoa só forma, por isso, um centro de interioridade, na medida em que, a um mesmo tempo, se expõe às relações interpessoais estabelecidas a nível da comunicação. (Habermas, 1999, pp. 69-70)

Mead e Habermas entendem que a individuação dos sujeitos não ocorre de modo direto ou por herança genética. Os sujeitos humanos sofrem processo de individuação na medida em que se tornam membros de uma comunidade de linguagem e de um mundo da vida partilhado intersubjetivamente.

simbólica apenas na linha que desemboca no agir regulado por normas, descuidando da linha que leva a uma comunicação linguística diferenciada em termos proposicionais" [ênfase no original] (Habermas, 2012b, p. 45).

${ }^{9}$ Habermas (2002a) dá-se conta de que "não é o emprego de proposições per se, mas antes o uso comunicativo de uma linguagem estruturada em proposições que é peculiar à nossa forma de vida sociocultural e constitui o estágio da reprodução genuinamente social da vida" [ênfase no original] (pp. 433-434). 


\section{pro.posıções}

$e$-ISSN 1980-6248

http://dx.doi.org/10.1590/1980-6248-2016-0046

Uma pessoa é uma personalidade porque ela pertence a uma comunidade, porque incorpora as instituições dessa comunidade à sua própria conduta. Adota a linguagem dessa comunidade como um meio mediante o qual desenvolve sua personalidade e depois, através de um processo de adoção dos diferentes papéis que lhe proporcionam todos os outros membros, ela acaba adotando a atitude dos membros da comunidade. Tal é, em certo sentido, a estrutura da personalidade de um homem.... A estrutura, pois, sobre a qual está construído o self é esta resposta comum a todos, pois um sujeito tem que ser membro de uma comunidade para ser si mesmo. (Mead, 1992, p. 162)

Ao interagir com outro membro de seu grupo social, o indivíduo passa a 'adotar as atitudes do outro', internalizando, desse modo, o mecanismo que possibilita a utilização dos papéis comunicativos do falante e do ouvinte. Com isso, os sujeitos abrem a possibilidade de interagir como "um ego que dá a entender algo a um alter ego" (Habermas, 2012b, p. 27). Esse interagir de um sujeito A com um sujeito B está na base do desenvolvimento da competência normativa de agir conforme papéis ou normas sociais.

Mead e Habermas reconhecem que a infância é o período fecundo para a criança vivenciar a experiência da estruturação simbólica da linguagem, internalizando a lógica normativa de agir conforme papéis sociais. Destarte, "entra em jogo a progressiva apropriação moral e sociocognitiva da estrutura de papéis que permitem regular legitimamente relações interpessoais" (Habermas, 2012b, p. 63). No período da infância, o brincar (play) e o jogar (game) são exemplos de como ocorre o processo de estruturação do self.

Ao brincar, a criança adota vários papéis, um depois do outro, de pessoas ou animais, que de algum modo se fazem presentes em sua vida. A vivência de outros papéis possibilita-lhe transcender a barreira de si mesma, em direção a uma organização de atividades sociais, nas quais a centralidade no próprio ego começa a ser rompida pela existência de uma noção de um 'outro' e de um 'nós'. O brincar antecede os jogos organizados e consiste num brincar algo, brincar alguma coisa ${ }^{10}$. Esse brincar livre, sem regras aparentes e por um período temporário, organiza uma estrutura de conversação interior. Ao dizer algo, assumindo uma personagem, e ao responder em outra personagem, a criança experimenta uma estrutura organizada de papéis sociais.

O brincar antecipa uma segunda fase, que possibilitará a estruturação do 'outro generalizado'. Esse estágio é exemplificado por Mead pela atividade dos jogos organizados

\footnotetext{
${ }^{10}$ De acordo com Mead (1992), "a criança brinca de ser uma mãe, um professor, um policial; ou seja, como dizemos, adota diferentes papéis" (p. 150).
} 


\section{pro.posições}

$e$-ISSN 1980-6248

http://dx.doi.org/10.1590/1980-6248-2016-0046

(game), na qual cada jogador deve ser capaz de representar um papel em um contexto coletivo e com regras próprias. O êxito ou a vitória de uma equipe sobre a outra dependem da capacidade de organização e de coordenação de seus membros, do atendimento às regras do jogo e da articulação dos papéis de cada um dos envolvidos.

O brincar (play) antecede o jogar (game). Pois em um jogo (game) há um procedimento regulado e normas. A criança deve adotar não somente o papel do outro, como ela faz no brincar, mas deve assumir os vários papéis de todos os participantes do jogo e governar suas ações de acordo com isso.... E essas reações organizadas se convertem no que denominamos de outro generalizado (generalized other), que acompanha e controla sua conduta. A presença desse outro generalizado em sua experiência é o que proporciona um self para si [ênfase no original]. (Mead, 1981, p. 285)

O 'outro generalizado' consiste na antecipação das expectativas de comportamentos normatizadas pela comunidade. Trata-se da vontade coletiva, expressa em termos de regras, convenções, leis e costumes, que intervém nas atitudes dos indivíduos. Seu desenvolvimento somente é possível com a introdução da figura de um terceiro integrante da interação: o observador. Com isso,

o ego poderá subdividir o papel comunicativo desempenhado pelo alter nos papéis de um alter ego, isto é, de outro participante e de um neuter, ou seja, o papel daquele que assiste à comunicação na qualidade de um membro do grupo. (Habermas, 2012b, pp. 67-68)

A introdução da figura de um terceiro componente da interação possibilita a relativização dos papéis de falante e ouvinte, tornando possível o intercâmbio desses papéis, bem como a emergência de uma convenção normativa.

É importante acrescentar que, em seus escritos, Mead (1992) postula a formação da identidade a partir de uma bipartição do self, diferenciando o 'eu' (I) do 'me/mim' (me) e, ao mesmo tempo, explicitando a dinâmica dialética que se instala no interior do self, a partir da qual “o 'eu' (I) reage ao self, que se originou por meio da adoção das atitudes dos outros” (p. 174). O 'me/mim' se origina da internalização das atitudes dos outros, especialmente da assunção da perspectiva generalizada dos controles de comportamento do grupo social ${ }^{11}$. Desse modo, o 'mim' condensa a experiência social do indivíduo, as expectativas de comportamento da

11 Para Habermas (2012b), "pelo caminho da internalização de papéis sociais, forma-se aos poucos uma estrutura de superego que possibilita ao agente se orientar por pretensões de validade normativas” (p. 77). 


\section{pro.posıções}

$e$-ISSN 1980-6248

comunidade para com esse indivíduo e os dispositivos de controle social na forma de um superego internalizado.

O 'eu', como uma dimensão pessoal que se contrapõe ao 'mim', não é redutível à convenção coletiva do 'outro generalizado' que foi internalizada. $O$ 'eu' constitui-se na dimensão não previsível do self, no elemento que nos identifica como únicos e singulares. Ele emerge da ação criativa do indivíduo diante de uma situação social; é uma reação que não pode ser prevista, tampouco antecipada, consistindo numa espécie de novidade do momento.

O $\ell$, pois, nessa relação entre o $e$ e o mim, é algo que, por assim dizer, responde a uma situação social que se encontra dentro da experiência do indivíduo. É a resposta que o indivíduo tem às atitudes que outros adotam em direção a ele, quando ele adota uma atitude em relação a eles. Assim sendo, as atitudes que ele adota em relação a eles estão presentes em sua própria experiência, porém sua resposta a elas conterá um elemento de novidade. O eu proporciona a sensação de liberdade, de iniciativa [ênfase no original]. (Mead, 1992, p. 177)

Entendemos que essa compreensão do self como uma construção histórica, interativa e simbólica resguarda a historicidade do ser humano e recoloca o problema da formação como uma tarefa individual e social, ao mesmo tempo. Se cada ser humano necessita vivenciar um processo de socialização para individuar-se, destacam-se a importância e o papel do 'outro' na formação do 'eu', sem demérito para os processos individuais e subjetivos.

\section{[ii] Aprendizagem, formação e desenvolvimento da identidade pessoal}

A constituição da identidade pessoal ocorre, segundo Habermas, mediante processos contínuos de aprendizagem que implicam desenvolvimento cognitivo, moral e interativo, englobando determinadas competências e estruturas internas, comuns a todos os indivíduos. Aprender é algo inerente ao ser humano, visto que não seria possível que não aprendessem ${ }^{12}$. Mead reconhece que as pessoas aprendem e desenvolvem-se por meio do processo de socialização, com a internalização das estruturas simbólicas disponíveis na interação e na comunicação. Por isso, podemos afirmar que os progressos cognitivo e moral do sujeito

\footnotetext{
${ }^{12}$ De acordo com Eder (2001), uma pressuposição presente em Habermas indica que "não aprender é impossível" (p. 23), ou seja, Habermas pressupõe que "os seres humanos são forçados por sua natureza a aprender". Repa (2008) reconhece no conceito de aprendizado utilizado por Habermas uma estreita conexão com o estruturalismo genético de Piaget. Afirma que esse conceito passa a ter "um papel central na concepção habermasiana de reconstrução evolutiva" (p. 142).
} 


\section{pro.posıções}

$e$-ISSN 1980-6248

http://dx.doi.org/10.1590/1980-6248-2016-0046

ocorrem concomitantemente ao desenvolvimento da competência interativa, à aquisição do saber cultural e à capacidade de estabilizar um autoentendimento.

A aprendizagem possui uma função importante porque possibilita, desde a perspectiva dos sujeitos, a construção e a reconstrução dos componentes estruturais do mundo da vida, os quais são expressos em saberes culturais acerca do mundo objetivo, em saberes referentes ao mundo social, entendidos como saberes éticos e políticos, e em saberes de si mesmo, ou autoexpressivos e estéticos. Por essa razão, a aprendizagem é fundamental no desenvolvimento da identidade pessoal.

Devemos destacar que em Habermas existem ao menos duas acepções distintas de identidade, formuladas ao longo do tempo ${ }^{13}$. A primeira concepção abarca os escritos Conbecimento e interesse (1982), cujo original foi publicado em 1968, e Para a reconstrução do materialismo bistórico (1983), publicado em 1976. Nesses dois textos, Habermas afirma que a identidade pessoal consiste mais em um processo do que em uma substância estável. Ela se forma desde o nascimento e perdura pelo transcorrer de toda a existência, sendo o "resultado das realizações de identificação da própria pessoa” (Habermas, 1983, p. 21), que permitem assegurar a continuidade e a estabilidade do autoentendimento e de uma imagem de si mesmo num contexto social. Desse modo, a identidade pessoal denota a capacidade que o indivíduo possui de manter a unidade da personalidade, num sentido vertical da sua biografia, mesmo diante de situações de conflito ou de transposição dos estágios e dos níveis de desenvolvimento. Tal unidade também é pressuposta na dimensão horizontal da existência, na interação com os demais, no enfrentamento das expectativas alheias e nos momentos limitantes de decisões cognitivas ou prático-morais. Nesse período, Habermas (1983) reconhece a existência de três níveis de identidade: identidade natural, identidade de papéis e identidade do $\mathrm{Eu}^{14}$.

A segunda concepção de identidade presente nos escritos de Habermas foi formulada a partir da obra Teoria do agir comunicativo, publicada em 1981. Nessa obra, ele postula que a formação da identidade dos indivíduos ocorre concomitantemente aos processos de reprodução

\footnotetext{
${ }^{13}$ Para essa diferenciação, utilizamo-nos do artigo publicado por Lima (2012).

14 Além disso, consoante Lima (2012), é importante destacar que, nos textos desse período estão em jogo três tradições teóricas diferentes: "a psicologia analítica do Eu ..., a psicologia cognitiva do desenvolvimento ... e a teoria da ação definida pelo interacionismo simbólico" (p. 255).
} 


\section{pro.posıções}

$e$-ISSN 1980-6248

dos componentes estruturais do mundo da vida - cultura, sociedade e identidade - por meio do agir comunicativo.

Sob o aspecto funcional do entendimento, o agir comunicativo se presta à transmissão e à renovação de um saber cultural; sob o aspecto da coordenação da ação, ele possibilita a integração social e a geração da solidariedade; e, sob o aspecto da socialização, o agir comunicativo serve à formação de identidades pessoais [ênfase no original]. (Habermas, 2012b, p. 252)

Em Teoria do agir comunicativo, Habermas analisa e incorpora as intuições de Mead relativas à interação, à socialização e à formação do self. Nesse sentido, merece destaque também Pensamento pós-metafísico (2002b), editado no ano de 1988, em que Habermas (2002b) expõe o conceito de identidade nos seguintes termos:

A identidade de indivíduos socializados forma-se simultaneamente no meio do entendimento linguístico com outros e no meio do entendimento intra-subjetivo-histórico-vital consigo mesmo. A individualidade forma-se em condições de reconhecimento intersubjetivo e de autoentendimento mediado intersubjetivamente. (pp. 186-187)

Ademais, Habermas (2002b) apresenta o desenvolvimento da identidade desde a perspectiva da interação e da individuação social em duas fases: a identidade moral convencional e a identidade moral pós-convencional, como veremos na sequência.

O desenvolvimento da identidade moral convencional principia com a internalização de determinados papéis e normas sociais. Nesse aspecto, Habermas segue a argumentação já proposta por Mead, ou seja, a de que a gênese da identidade convencional coincide com a evolução dos níveis de comunicação, a partir do desenvolvimento de um nível de linguagem proposicionalmente diferenciada, que possibilita a estruturação simbólica do mundo objetivo, social e subjetivo num nível ontogenético. A construção do mundo subjetivo se dá em conformidade com a construção do mundo social, a partir da aprendizagem dos papéis normativos sociais, mediante internalização das expectativas de comportamento, que "imigram para o interior da pessoa" (Habermas, 2002b, p. 214).

É fundamental destacar que a identidade convencional permanece ainda presa às convenções práticas de um grupo particular. Ela representa uma vontade coletiva que age sobre o indivíduo. Por isso, segundo Habermas (2002b), “a identidade-eu convencional é, no melhor dos casos, lugar-tenente da verdadeira” (p. 216), a identidade do eu pós-convencional, que se ampara em processos de individuação e nas experiências de emancipação. 


\section{pro.posições}

$e$-ISSN 1980-6248

http://dx.doi.org/10.1590/1980-6248-2016-0046

A identidade pós-convencional é caracterizada por Habermas como uma identidade afirmada por conta própria e implica a capacidade de agir autonomamente, orientar a própria ação em bases universais e realizar-se a si mesmo como uma vida assumida responsável e autonomamente. A configuração dessa classe de identidade denota o desenvolvimento da capacidade de autorrealização e autodeterminação. Configura-se, assim, como possibilidade de que o sujeito assuma a própria vida de modo responsável e autônomo, sendo capaz de dar razões, por intermédio da argumentação e do discurso, acerca de que homem é no presente e, ao mesmo tempo, de que homem deseja ser no futuro.

Somente quem assume sua história de vida tem condições de ver nela a realização de si mesmo. Assumir responsavelmente uma biografia significa, em primeiro lugar, adquirir clareza sobre quem queremos ser. E, em segundo lugar, implica considerar as pegadas das próprias interações como se fossem sedimentações das ações de um autor imputável; portanto, de um sujeito que agiu no terreno de uma relação autorrefletida. [ênfase no original] (Habermas, 2012b, pp. 180181).

Mediante a assunção da própria biografia, pode a pessoa autorrealizar-se e pressupor pretensão de originalidade e de insubstituibilidade ${ }^{15}$. Isto é, embora o ser humano constitua sua própria identidade numa relação com outros seres humanos, no recurso a uma comunidade comunicativa, ela somente será concretizada na perspectiva de uma construção de sentido para a própria existência. Isso leva à seguinte afirmação de Habermas (2002b):

Uma vez que agora se articula uma identidade-eu através de uma pretensão incondicionada de singularidade e de insubstituibilidade, a qual não se prende mais exclusivamente ao "tipo social", sendo, pois, pós-convencional, também desta vez entra em jogo um momento de idealização. Esse momento não se refere somente ao círculo virtual que abrange todos os destinatários, a comunidade ilimitada de comunicação, mas a própria pretensão de individualidade; ele diz respeito à garantia que eu assumo conscientemente em relação à continuidade de minha história de vida, à luz de um projeto de vida individual e refletido. [ênfase no original] (p. 220)

O ser humano, para desenvolver uma identidade do eu, deverá, portanto, constituir uma autorreferência simbólica de si mesmo, um mundo subjetivo de sentido, e necessitará desenvolver a capacidade de agir comunicativamente e mediante as normas convencionalmente estabelecidas. Além disso, deverá ser capaz de olhar para a própria existência, dotá-la de sentido

15 Em conformidade com Habermas (2012b), os dois aspectos da identidade do eu, autodeterminação e autorrealização, são ilustrados por Mead com o recurso a sentimentos como o respeito a si mesmo (self-respect) e o sentido de superioridade (sense of superiority), ou valorização de si mesmo, os quais são recursos necessários para o autorreconhecimento e para a confirmação do valor subjetivo de si. 


\title{
pro.posıções
}

$e$-ISSN 1980-6248

e decidir-se acerca de que tipo de ser humano quer ser no futuro, numa tríplice relação: consigo mesmo, com o outro e com o mundo.

\begin{abstract}
"Eu" me compreendo como "pessoa em geral" e como "indivíduo inconfundível" que não se deixa substituir por ninguém em sua biografia. Sou pessoa em geral na medida em que tenho em comum com todas as outras pessoas as propriedades essenciais de um sujeito que conhece, fala e age. Sou ao mesmo tempo um indivíduo inconfundivel, que responde, de maneira insubstituível, por uma biografia tão formadora quanto singular. No entanto, não adquiri essa autocompreensão como pessoal em geral e como indivíduo senão por ter crescido numa determinada comunidade. [ênfase no original] (Habermas, 2004b, pp. 195-196)
\end{abstract}

A esse novo tipo de identidade exigida, a identidade pós-convencional, corresponde um processo progressivo de individuação, de autonomia, de autodeterminação e de autorrealização. Ao referir-se a si mesmo como 'eu', o ser humano demonstra que pode ser identificado como ser genérico, capaz de fala e de ação e, ao mesmo tempo, como indivíduo circunstanciado, capaz de agir autonomamente e de dar continuidade à sua própria vida, assumindo-a e responsabilizando-se por ela.

\section{[iii] Educação e formação da identidade}

A compreensão de Mead e de Habermas, no que concerne à formação da identidade pessoal, permite-nos reinterpretar o conceito de educação desde a perspectiva da intersubjetividade e dos processos interativos nela implicados. Ademais, tal compreensão possui potencial para auxiliar a repensar as ações formativas escolares com a reposição da interação, da cooperação solidária e da ludicidade como dimensões formativas, com a mesma importância dos conteúdos cognitivos, das habilidades e das competências.

Se concordarmos com as indicações de Mead e de Habermas de que a educação é, em certo sentido, interação, então as práticas pedagógicas escolares não podem prescindir da interação, do contato com o outro e da convivência enquanto ações fundamentais à aprendizagem e ao desenvolvimento dos educandos. A interação permite a aprendizagem de estratégias de entendimento acerca de coisas, de fatos e de situações do mundo objetivo, subjetivo e social. Além disso, a convivência consiste em pré-requisito à socialização e à individuação. Por isso, no ambiente escolar, ela se torna pressuposto à formação de uma identidade do eu mais autônoma, madura e descentrada. Opções e práticas pedagógicas que 


\section{pro.posições}

http://dx.doi.org/10.1590/1980-6248-2016-0046

\section{$e$-ISSN 1980-6248}

incentivem o individualismo, ou mesmo a falta de convivência social, não se sustentam, se confrontadas com os pressupostos que temos aqui defendido ${ }^{16}$.

A interação e a convivência, como situações formativas, necessitam ser mediadas, pressupondo a presença e a ação do educador. $\mathrm{O}$ educador, além de representar a dimensão institucional da comunidade, torna-se partícipe dos processos de aprendizagem. Ele é também o interlocutor da geração adulta, o porta-voz das intencionalidades, dos desejos, das preocupações e dos cuidados da sociedade com os seus novos membros.

Agir e interagir com o outro pressupõe empatia, reciprocidade e o reconhecimento desse outro como ser livre e distinto, dotado de direitos e de deveres. Exige saída de si mesmo e aceitação de que o outro possa possuir perspectivas e sentidos distintos. Entendemos que a instituição escolar pode auxiliar efetivamente na formação da moralidade e na progressão da capacidade de julgar dos sujeitos. Auxiliará mediante ações e práticas pedagógicas que priorizem situações de entendimento mútuo, de discernimento e de coordenação dos interesses e das ações dos diversos grupos. Essa modalidade de formação exige ações pedagógicas que valorizem o diálogo, a argumentação, o reconhecimento dos melhores argumentos e a busca de consensos. Ademais, a práxis pedagógica pode propiciar instâncias de discussão e de reflexão acerca da gênese das normas e dos valores, dos seus significados e da importância disso para a manutenção da vida em comunidade. Com isso, facultará aos educandos a organização de outras imagens da sociedade e de si mesmos, bem como os rudimentos de uma identidade do eu mais evoluída, autônoma e descentrada.

Também o brincar e o jogar consistem em estratégias pedagógicas válidas para a consecução das intencionalidades de qualquer projeto educativo. Mead (2008) apontou o brincar como o princípio a partir do qual a educação deveria ser conduzida, visto consistir num fundamento natural do desenvolvimento do ser humano. Nas atividades lúdicas é facultado à criança vivenciar e desenvolver a espontaneidade, a imaginação e a criatividade. Por meio do brincar, é possível o contato direto e a experiência com os objetos, com a natureza e com formas de organização e de coordenação social. Os jogos, mais organizados, permitem a estruturação

\footnotetext{
${ }^{16}$ Referimo-nos a algumas práticas, adotadas por famílias em centros de maior densidade populacional, de educar seus filhos em casa, dispensando a escola e fomentando certo modo de isolamento social. Entendemos que esse tipo de prática, mesmo diante de argumentação contrária, restringe o desenvolvimento de dimensões fundamentais da identidade do ser humano, especialmente no que tange ao processo de socialização.
} 


\section{pro.posıções}

$e$-ISSN 1980-6248

http://dx.doi.org/10.1590/1980-6248-2016-0046

da noção de regras e demandam coordenar as ações dos vários componentes da equipe em vista de um objetivo comum.

Ao considerar as atividades lúdicas no rol das ações pedagógicas, a educação escolar estará contribuindo com o desenvolvimento da criança e do adolescente. Aprender brincando ou jogando é mais prazeroso do que mediante exercícios ou técnicas que apenas valorizem a dimensão intelectual. Com isso, não estamos dizendo que a educação escolar deve negar os conteúdos mínimos ou mesmo furtar-se ao exercício conceitual. Apenas enfatizamos que a dimensão lúdica é também fundamental para o humano e que merece ser desenvolvida, especialmente a partir de atividades que enfatizem o brincar e o jogar.

\section{Considerações finais: implicações à formação}

A posição de G. H. Mead e de J. Habermas explicitada até aqui - de que a formação da identidade do eu se dá em processos interativos - encontra-se ajustada às exigências de uma sociedade radicalmente plural, justamente porque o caráter intersubjetivo da formação abre espaço para os elementos distintos, de inovação e de diferença, reivindicados pela pluralidade do mundo e pela presença do outro. Os processos interativos colocam-nos diante do estranho, num confronto com outras perspectivas, sensibilizando-nos para aquilo que ultrapassa nossa cosmovisão, numa constante aprendizagem e ampliação de horizontes. Em outras palavras, as experiências que desestabilizam as certezas e questionam os valores morais possibilitam reorganizar e ampliar o eu. Como esse eu não tem mais uma essência ou substância fixa, a possibilidade de autocriação ocorre nas relações intersubjetivas, nas escolhas e na apropriação reflexiva da própria biografia.

A imagem que Habermas (2005) usa da constituição da subjetividade, "representada como se fora uma luva virada do avesso, a qual põe à mostra a estrutura de suas malhas tecidas com os fios da intersubjetividade" (p. 16), indica que, além do eu se constituir em processo de interação social, o outro desde já está pressuposto numa rede de interações. Nessa medida, fora da relação com o outro nada somos, pois a identidade envolve o confronto com aquilo que não é igual ao eu, aquilo que é irracional, não controlável. Assim, a autoconsciência não é fruto de uma subjetividade isolada, mas depende de uma alteridade que a constitua. Sobre isso, Habermas (2005) afirma: 


\section{pro.posições}

e-ISSN 1980-6248

http://dx.doi.org/10.1590/1980-6248-2016-0046

Jamais consegui aceitar a ideia de que a autoconsciência constitui, por si mesma, um fenômeno originário. Ou não será verdade que nós só nos tornamos conscientes de nós mesmos nos olhares que um outro lança sobre nós? Nos olhares de um $t u$, de uma segunda pessoa que fala comigo na primeira pessoa, eu me torno consciente de mim mesmo, não somente como um sujeito capaz de vivenciar coisas em geral, mas também e, ao mesmo tempo, como um eu individual. Os olhares subjetivadores do outro possuem uma força individuadora. (p. 19)

A interação e a experiência da convivência em ambiente escolar constituem-se, desde a perspectiva aqui delineada, em instâncias formativas primordiais, complementando as aprendizagens no plano intelectual dos sujeitos. Isto é, entendemos que a convivência em grupo e o contato com os outros conformam reais situações de aprendizagem, visto que pressupõem o desenvolvimento da sensibilidade, da empatia, da solidariedade e da capacidade de entendimento, pré-requisitos à vida em sociedade. Ao mesmo tempo, a experiência interativa demanda dos sujeitos capacidade de descentramento, o que instiga a flexibilização de um olhar apenas para si mesmo e a necessária abertura ao outro.

A intersubjetividade, pressuposta e presente no interacionismo simbólico e no agir comunicativo, implica o entrecruzamento da perspectiva individual com a coletiva. Isso requer imparcialidade do ponto de vista moral, o que fratura a subjetividade e leva o indivíduo a adotar a atitude performativa de participante. O conceito de autonomia, proposto intersubjetivamente, considera que o desenvolvimento da personalidade de cada um depende da realização da liberdade de todos. Em relação a esse aspecto, incide a questão da formação, ou seja, o empenho para assegurar a interiorização da consciência moral, que seja capaz de agir autonomamente, com respeito a si mesmo e ao outro. É necessário, como diz Habermas (1992), que

exista certa harmonia entre esta moral universalista e as práticas de socialização e educação, que se constroem no controle da consciência (que é interiorizado) e que promovam identidades individuais relativamente abstratas. Uma moral universalista necessita também de uma certa harmonia com aquelas instituições políticas e sociais, nas quais já estão incorporadas concepções jurídicas e morais pós-convencionais. (p. 25)

Pelo processo de socialização, o sujeito interioriza estruturas simbólicas (valores, visões de mundo e normas de ações) e adquire competência linguística para que se mantenha numa rede de relações sociais (integração social), permitindo a efetivação da moral universalista. Contudo, como sabemos, apostar numa moral universal não significa a garantia de sua aplicação, porquanto a interiorização de valores e de normas de ação depende de um processo de aprendizagem. Habermas (2012a) destaca que "o modelo normativo de ação mune os atores 


\section{pro.posıções}

$e$-ISSN 1980-6248

http://dx.doi.org/10.1590/1980-6248-2016-0046

não apenas de um 'complexo cognitivo', mas também de um 'complexo motivacional' que possibilita um comportamento adequado à norma" (p. 172). Em outra ocasião, destacamos o problema que se estabelece para o campo prático - em especial para a educação - quando uma moral universalista não consegue assegurar as formas de vida que tornem possível a formação da vontade e a qualidade das relações intersubjetivas (Hermann, 1999). Nesse aspecto incide a responsabilidade da educação escolar, para favorecer momentos de experiência e de aprendizagem que preparem os alunos para novas organizações do eu, para a participação em argumentos que esclareçam as decisões morais e para a responsabilização de suas ações. Se a educação e a socialização fraudam essas expectativas, teremos como resultado um desnível entre juízo e ação, que Habermas (1992) reconhece ser bastante problemático:

Frequentemente faltam as instituições que poderiam proporcionar, em nível social, a formação discursiva da vontade em relação a determinados temas e lugares; muitas vezes faltam os processos de socialização que permitem a aquisição das disposições e capacidades necessárias a uma participação em argumentações morais. (p. 27)

Evidentemente a formação da identidade do eu num plano pós-metafísico já se afastou da ideia de que possa haver garantias do agir e passa a operar, considerando a negatividade da experiência como um elemento decisivo para a aprendizagem, tanto individual como social. Isto é, pode-se aprender com as expectativas fraudadas, visto que, com isso, reconhecemos nossos limites e o que nos falta. Reconhecimento esse decisivo para a responsabilização de nossas ações.

Aqueles que se envolvem com a formação/educação devem considerar a relevância dos processos interativos para o esclarecimento moral. Pela discursividade e pelo diálogo, confrontamo-nos com outras posições e ampliamos nosso horizonte interpretativo, o que faculta ao indivíduo atingir níveis mais complexos de julgamento moral e de adesão, refletida, a determinados valores e crenças. Todavia, a tais processos não devemos associar a expectativa ingênua de que haveria imediata interiorização das normas. Ao contrário, aí se instalam conflitos e tensões que desafiam o eu.

Por conseguinte, nenhum processo formativo pode deixar de considerar o papel da aprendizagem no espaço da educação escolar, particularmente as possibilidades de discussão sobre a pluralidade de orientações valorativas que caracterizam as sociedades contemporâneas e abrem espaço para que a formação de uma identidade se estruture a partir da adesão voluntária a valores. Portanto, uma sociedade que reduz tais processos apenas à dimensão cognitiva (acesso 


\section{pro.posıções \\ $e$-ISSN 1980-6248}

http://dx.doi.org/10.1590/1980-6248-2016-0046

aos conhecimentos e às competências) perde a riqueza que a tradição da Paideia, da Humanitas e da Bildung nos legou - que a educação tem uma reivindicação histórica de formação ética intimamente vinculada à formação da identidade do eu.

\section{Referências}

Casagrande, C. A. (2009). Educação, intersubjetividade e aprendizagem em Habermas. Ijuí: Ed. Unijuí.

Casagrande, C. A. (2012). A formação do eu em Mead e em Habermas: desafios e implicações à educação. Tese de Doutorado em Educação, Pontifícia Universidade Católica do Rio Grande do Sul, Porto Alegre, RS, Brasil.

Casagrande, C. A. (2014). G. H. Mead \& a educação. Belo Horizonte: Autêntica.

Cenci, A. V., Dalbosco, C. A., \& Mühl, E. H. (Orgs.). (2009). Sobre filosofia e educação: racionalidade, diversidade e formação pedagógica. Passo Fundo: Ed. Universidade de Passo Fundo.

Dölmen, R. (2001). Entdeckung des ich: die geschichte der individualisierung von mittelalter bis zur gegenwart. Köln: BöhlauVerlag GmbH \& Cie.

Edelstein, W., \& Nunner-Winkler, G. (2005). Morality in context. Amsterdam: Elsevier.

Eder, K. (2001). As sociedades aprendem, mas o mundo é difícil de mudar. Lua Nova: Revista de Cultura e Política, 53, 05-28.

Habermas, J. (1982). Conhecimento e interesse. Rio de Janeiro: Zahar.

Habermas, J. (1983). Para a reconstrução do materialismo histórico. São Paulo: Brasiliense.

Habermas, J. (1992). Erläuterungen zur diskursethik. Frankfurt am Main: Suhrkamp.

Habermas, J. (1999). Comentários à ética do discurso. Lisboa: Instituto Piaget.

Habermas, J. (2002a). O discurso filosófico da modernidade: doze lições. São Paulo: Martins Fontes.

Habermas, J. (2002b). Pensamento pós-metafísico: estudos filosóficos (2a ed.). Rio de Janeiro: Tempo Brasileiro. 


\section{pro-posıções}

$e$-ISSN 1980-6248

http://dx.doi.org/10.1590/1980-6248-2016-0046

Habermas, J. (2002c). Agir comunicativo e razão destranscendentalizada. Rio de Janeiro: Tempo Brasileiro.

Habermas, J. (2002d). Racionalidade e comunicação. Lisboa: Edições 70.

Habermas, J. (2003). Consciência moral e agir comunicativo (2a ed.). Rio de Janeiro: Tempo Brasileiro.

Habermas, J. (2004b). Verdade e justificação: ensaios filosóficos. São Paulo: Loyola.

Habermas, J. (2004c). O futuro da natureza humana: a caminho de uma eugenia liberal? São Paulo: Martins Fontes.

Habermas, J. (2005). Zwischen naturalismus und religion: philosophische aufsätze. Frankfurt am Main: Suhrkamp.

Habermas, J. (2010). Obras escolhidas: fundamentação linguística da sociologia. Lisboa: Edições 70.

Habermas, J. (2012a). Teoria do agir comunicativo, 1: racionalidade da ação e racionalização social. São Paulo: Martins Fontes.

Habermas, J. (2012b). Teoria do agir comunicativo, 2: sobre a crítica da razão funcionalista. São Paulo: Martins Fontes.

Hermann, N. (1999). Validade em educação: intuições e problemas na recepção de Habermas. Porto Alegre: Edipucrs.

Hermann, N. (2001). Pluralidade e ética em educação. Rio de Janeiro: DP\&A.

Hermann, N. (2005). Ética e estética: a relação quase esquecida. Porto Alegre: Edipucrs.

Hermann, N. (2010). Autocriação e horizonte comum: ensaios sobre educação ético-estética. Ijuí: Ed. Unijuí.

Hermann, N. (2014a). A questão do outro e o diálogo. Revista Brasileira de Educação, 19(57), 477-493.

Hermann, N. (2014b). Ética \& educação: outra sensibilidade. Belo Horizonte: Autêntica.

Honneth, A. (2009). Crítica del agravio moral: patologías de la sociedad contemporánea. Buenos Aires: Fondo de Cultura Económica: Universidad Autónoma Metropolitana. 


\section{pro.posıções}

$e$-ISSN 1980-6248

http://dx.doi.org/10.1590/1980-6248-2016-0046

Lima, A. F. (2012). Acepções de identidade na obra de Jürgen Habermas: subsídios para uma psicologia social criticamente orientada. Psicologia \& Sociedade, 24(2), 253-262.

Mead, G. H. (1981). Selected writings. Chicago: The University of Chicago Press.

Mead, G. H. (1984). On social psychology. Chicago: The University of Chicago Press.

Mead, G. H. (1992). Mind, self, \& society: from the standpoint of a social behaviorist. Chicago: The University of Chicago Press.

Mead, G. H. (2002). The philosophy of the present. Amherst, New York: Prometheus Books.

Mead, G. H. (2006). Play, school, and society. New York: Peter Lang Publishing.

Mead, G. H. (2008). The philosophy of education. Boulder, CO: Paradigm Publishers.

Montaigne, M. (1972). Ensaios. São Paulo: Abril Cultural.

Nunner-Winkler, G. (2011). Formação da identidade em tempos de mudanças velozes e multiplicidade normativa. Educação, 34(1), 56-64. Retirado em 26 de março de 2015, de: http://revistaseletronicas.pucrs.br/ojs/index.php/faced/article/view/8671/6128

Pessoa, F. (1999). Obra poética. Rio de Janeiro: Aguillar.

Píndaro. (1947). The odes of Pindar. Chicago: The University of Chicago Press.

Platão. (1997). Complete works. Indianapolis, Indiana: Hackett Publisching Company.

Repa, L. (2008). A transformação da filosofia em Jürgen Habermas: os papéis de reconstrução, interpretação e crítica. São Paulo: Singular; Esfera Pública.

Sass, O. (2004). Crítica da razão solitária: a psicologia social segundo George Herbert Mead. Bragança Paulista: Editora Universitária São Francisco.

Submetido à avaliação em 24 de junho de 2015; aceito para publicação em 16 de setembro de 2016. 